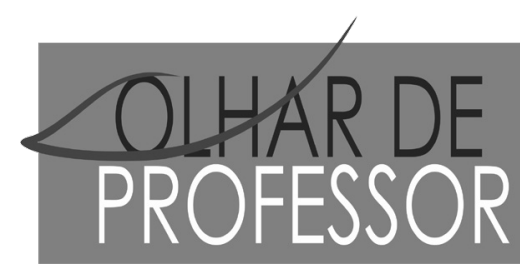

DOI: 10.5212/OLHARPROFR.v.2112.0004

\title{
LEITURA DE TEXTOS DE DIVULGAÇÃO CIENTíFICA PARA CRIANÇAS: OS LETRAMENTOS EM QUESTÃo
}

\author{
READING OF SCIENTIFIC DISCLOSURE TEXTS FOR CHILDREN: THE LITERACIES IN QUESTION \\ LECTURA DE TEXTOS DE DIVULGACIÓN CIENTíFICA PARA NIÑOS: LAS LETRAMIENTOS EN CUESTIÓN
}

\author{
DAIANE QUADROS DE OLIVEIRA* \\ ROBERTA SCHNORR BUEHRING **
}

\begin{abstract}
Resumo: No artigo se apresenta uma breve discussão sobre o uso do termo letramento na ciência e na estatística. Advoga-se que os processos de aprendizagem da leitura, de maneira crítica, não se restringem a componente curricular de Língua Portuguesa e devem ocorrer na escola de forma contextualizada. Realiza-se a análise de um texto de divulgação científica da revista online Ciência Hoje das Crianças (CHC), a fim de identificar a sua potencialidade no que tange ao letramento científico e estatístico no ensino de ciências e da matemática. O texto foi analisado por meio dos procedimentos da Análise Textual Discursiva (ATD). A análise foi organizada a partir de uma categoria a priori e uma emergente: linguagem matemática e estatística e relação entre ciência e tecnologia. Dentre os resultados podemos destacar que o texto permite trabalhar com conceitos importantes à linguagem estatística como média e intervalo; e permite problematizar compreensões sobre a atividade científico-tecnológica.
\end{abstract}

Palavras-chave: Leitura. Letramento científico. Divulgação científica para crianças.

Abstract: This paper presents a brief discussion about the use of the term literacy in science and statistics. It is argued that the learning processes of reading in a critical way are not restricted to the Portuguese Language curricular component and they should occur in school in a contextualized way. The analysis of a scientific dissemination text of the online magazine Ciência Hoje das Crianças (CHC) is carried out in order to identify its potential for scientific and statistical literacy for the teaching of science and mathematics. The text was analyzed through the procedures of the Discursive Textual Analysis (DTA). The analysis was organized from a priori and an emergent category: mathematical and statistical language and the relationship between science and technology. Among the results we can highlight that the text allows to work with important concepts to the statistical language as mean and intervals; and it allows to problematize understandings about the scientific-technological activity.

Keywords: Reading. Scientific literacy. Scientific disclosure to children.

Resumen: En el artículo se presenta una breve discusión sobre el uso del término alfabetización en la ciencia y la estadística. Se defiende que los procesos de aprendizaje de la lectura, de manera crítica, no se limitan al espacio curricular Lengua Portuguesa y deben ocurrir en la escuela de forma contextualizada. Se realiza el análisis de un texto de divulgación científica de la revista online Ciência Hoje das Crianças (CHC), con el fin de identificar su potencialidad en lo que se refiere a la alfabetización científica y estadística en la enseñanza de las ciencias y de las matemáticas. El texto fue analizado por medio de los procedimientos del Análisis textual Discursivo (ATD). Este análisis se organizó a partir de una categoría a priori y una emergente: lenguaje matemático y estadístico y la relación entre ciencia y tecnología. Entre los resultados podemos destacar que el texto permite trabajar con conceptos importantes para el lenguaje estadístico como promedio e intervalo; y permite problematizar comprensiones sobre la actividad científico-tecnológica.

Palabras claves: Lectura. Alfabetización científica. Divulgación científica para niños.

\footnotetext{
* Doutoranda do Programa de Pós-Graduação em Educação Científica e Tecnológica (PPGECT- UFSC)- daianeq.oliveira@ gmail.com

${ }^{* *}$ Professora da rede municipal da Prefeitura Municipal de Florianópolis e doutoranda do Programa de Pós-Graduação em Educação Científica e Tecnológica (PPGECT- UFSC)- robertaschb@gmail.com
} 


\section{INTRODUÇ̃̃̃O}

Silva (1998) diz que todo professor, independente de sua área, é um professor de leitura, visto que todas as componentes curriculares utilizam a oralidade e a escrita. Por sua vez, Zanetic (2006) enfatiza que a crise de leitura é um problema contemporâneo que não pode ficar restrita aos professores da componente curricular de Língua Portuguesa.

Ademais, o desafio da formação de leitores críticos reforça a necessidade dos professores de todas as disciplinas assumirem a responsabilidade da formação de leitores. (SILVA, 1998). Da mesma forma, a formação de sujeitos letrados em ciência, tecnologia e matemática passou a ser um compromisso de diversos profissionais da educação.

A partir da década de 1990, com a publicação dos Parâmetros Curriculares Nacionais passou-se a valorizar o uso de diferentes gêneros textuais na escola brasileira. Esse fato abriu portas para a leitura de textos científicos no ambiente escolar. Os textos de divulgação científica se tornou uma possibilidade de articular o ensino de leitura nas aulas de ciências na educação básica. Portanto, pesquisas da área de educação em ciências os sugerem como uma possibilidade de complementar os materiais didáticos tradicionais, como os livros didáticos. (FERREIRA; QUEIROZ, 2012).

No entanto, observa-se que ler na escola continua acontecendo predominantemente nas aulas de Língua Portuguesa. A materialização do texto ocorrida no ato da leitura continuou sendo uma atividade de reprodução fiel de cada palavra e cada ponto, na busca da ideia do autor como uma "autoridade máxima” do texto. (ALMEIDA, 2011).

Correia e Sauerwein (2017), apoiadas em interlocutores teóricos, destacam que a leitura de textos de divulgação científica permite que: o estudante tenha acesso a informações diversas, desenvolva a habilidade de leitura e de argumentação, se aproprie de conceitos científicos e elementos da terminologia científica.

Neste sentido, a leitura de textos de divulgação científica pode propiciar aos estudantes entrar em contato com conceitos científicos, tecnológicos e estatísticos, e a escola é o ambiente em que esses sujeitos podem ter a oportunidade de se familiarizar com essa linguagem e com o modo de "fazer ciência". Em vista disso, este artigo tem por objetivo apresentar a análise de um texto de divulgação científica para crianças, a fim de identificar potencialidades que permitam promover o letramento científico e estatístico.

Advogamos a leitura de textos científicos para crianças como parte do processo de formação de leitores críticos, ao mesmo tempo em que enfatizamos a formação em ciência, tecnologia e estatística. Entendemos por leitor crítico aquele que compreende as diferentes linguagens do texto, como a científico-tecnológica e a estatística, sendo capaz de ressignificar a leitura e transformar sua realidade.

Portanto, para iniciar a discussão, buscamos conceitos de letramento, letramento científico e letramento estatístico. Em seguida, discorremos sobre as características do discurso de divulgação científica e trazemos uma breve síntese sobre do que trata a revista Ciência Hoje das Crianças (CHC). Finalmente, a fim de identificar as potencialidades e os limites de um texto de divulgação científica voltado para o público infantil, no que se refere ao letramento científico-tecnológico e estatístico, investigamos um artigo da revista CHC de acordo com os procedimentos da Análise Textual Discursiva (ATD). Por meio da análise, foi identificada uma categoria a priori e uma emergente, a saber, linguagem matemática e estatística e a relação entre ciência e tecnologia. Essas duas categorias nos permitem questionar e refletir a leitura deste tipo de texto na escola com um grupo de crianças.

\section{OS MUITOS LETRAMENTOS}

A palavra "letramento" resulta da tradução do termo inglês literacy. De acordo com Soares (1999, p. 17) "literacy é o estado ou condição que assume aquele que aprende a ler e escrever." Está contida nesse conceito a ideia de que ler e escrever gera consequências sociais, culturais, políticas, econômicas, cognitivas e linguísticas para quem aprende essa habilidade e para o grupo social em que é inserida.

Letramento é, pois, o resultado da ação de ensinar ou de aprender a ler e escrever: o estado ou a condição que adquire um grupo social ou um indivíduo como consequência de ter-se apropriado da escrita. (SOARES, 1999, p. 18). 
Para considerar um sujeito letrado seria necessário mais do que ler e escrever e a partir dessa compreensão, a palavra "letramento" foi transposta para outras áreas como a ciência. Para Vitor e Silva (2017) a importação da expressão "scientific literacy" trouxe consigo alguns problemas: a possibilidade de traduzi-la simplesmente como "alfabetização ou letramento científico" sem uma maior reflexão sobre seu significado; e a variedade de sentidos possíveis para sua definição. Apesar da falta de consenso na literatura, importantes papeis são atribuídos para a educação e a alfabetização científica na autonomia dos estudantes. (VITOR; SILVA, 2017).

Em variadas situações de uso da língua, cada pessoa pode ler um mesmo enunciado de maneira diferente por diferentes razões e não seria diferente em relação ao termo letramento científico. As definições e ensaios sobre letramento científico se aproximam e se complementam. Para Chassot (2006, p. 40), é possível identificar um analfabeto na língua ou na matemática, no entanto, não é possível medir o analfabetismo científico, porque "ver o quanto alguém sabe ler as coisas do mundo natural é mais complexo". Essa tarefa torna-se mais subjetiva se pensarmos que há diferentes maneiras de ler as coisas do mundo natural, e a ciência é uma delas. No entanto, a falta de "uma" definição sobre o que seria um sujeito "letrado" ou "não letrado" cientificamente não diminui a relevância do tema e nem impede seu estudo e reflexão.

Sendo assim, de acordo com Santos (2007) a alfabetização e o letramento científicos são defendidos por diferentes profissionais e em variados contextos, por isso estamos longe de chegar a um consenso porque se trata de um conceito muito amplo. O contexto ao qual o autor se refere está relacionado ao ponto de vista do profissional que o defende, e também depende das situações sociais, culturais e históricas envolvidas:

O letramento dos cidadãos vai desde o letramento no sentido do entendimento de princípios básicos de fenômenos do cotidiano até a capacidade de tomada de decisão em questões relativas à ciência e tecnologia em que estejam diretamente envolvidos, sejam decisões pessoais ou de interesse público. (SANTOS, 2007, p. 480).

Ao ler um texto de divulgação científica, podemos nos deparar com conceitos e contextos que muitas vezes não estão explícitos no texto. De tal maneira que para "saber ler" um texto de divulgação científica é preciso, também, compreender as representações e a linguagem científica e matemática. Ambas constituem a linguagem e se fazem presentes nos textos de divulgação científica como forma de complementar a comunicação ou fornecer mais elementos para compreensão do leitor.

De acordo com Santos (2007, p. 478), a educação científica:

[...] desde o Ensino Fundamental até a pós-graduação vem sendo abordada cada vez mais com fragmentação e especialização. Dessa forma, as discussões sobre educação científica muitas vezes acabam por priorizar um domínio em relação a outro.

A preocupação com a especialização do conhecimento está na descontextualização, pois fora do contexto, o conhecimento pode perder o sentido e o letramento não acontece porque ele está relacionado às atitudes provindas da "condição" de ser letrado. Essas atitudes letradas ocorrem no contexto social, e pensando assim, a condição de ser um leitor também depende de outros conceitos "especializados” de letramento, sendo um deles o letramento estatístico. Os sujeitos letrados podem tirar as próprias conclusões por meio da linguagem estatística, a qual está inserida nos currículos de matemática do Ensino Básico.

A estatística requer interpretação frente às incertezas de um conjunto de variáveis que dizem respeito às diferentes áreas do conhecimento. Para que seja possível lidar com incertezas é preciso compreender o contexto e saber como se faz pesquisa estatística. Lopes confirma que "o pensamento estatístico requer habilidades muito diferentes daquelas empregadas na ciência matemática.” (Lopes, 2010, p. 60), isto porque na estatística podemos encontrar várias respostas a uma mesma pergunta, os caminhos podem ser muitos e é preciso interpretar com o contexto. Um problema estatístico "não tem uma solução única e não pode ser avaliado como totalmente errado ou certo, devendo ser avaliado em termos da qualidade do raciocínio, da adequação dos métodos utilizados à natureza dos dados existentes.” (Lopes, 2010, p. 55). 
Assim, a leitura e compreensão dos dados dependem também dos conhecimentos científicos prévios, das experiências do leitor e sua capacidade de investigar e de conectar diversas informações presentes na realidade. Como a leitura de qualquer texto, para "saber ler" representações estatísticas não basta decodificá-las, é preciso que o leitor estabeleça relações entre as informações ali contidas com a realidade que as cercam.

Quem produziu os dados, quais foram seus objetivos, qual a população escolhida, quais as fontes utilizadas e quais os métodos de coleta de dados são questionamentos importantes na leitura estatística. O olhar crítico para as informações é ingrediente necessário para a leitura de textos de divulgação científica e o conhecimento de como se faz uma pesquisa, uma coleta de dados e sua divulgação só têm a contribuir para esse olhar.

Por essa razão, abordamos a necessidade de aproximar e complementar os letramentos científico-tecnológico e estatístico, compreendendo a questão do letramento como um todo. A "separação" entre letramento científico-tecnológico e estatístico ocorre no exercício metalinguístico, se faz presente neste artigo apenas para o "dar-se conta" que as diferentes terminologias buscam um mesmo fim e dizem respeito a um mesmo sujeito. Acreditamos que no texto de divulgação científica para crianças que segue como exemplo, será possível perceber "um único letramento”.

\section{TEXTOS DE DIVULGAÇÃO CIENTÍFICA PARA CRIANÇAS}

Nos textos científicos, os conceitos científicos e tecnológicos costumam ser expressos por uma terminologia específica, caracterizados por um discurso rigoroso e preciso e situados no contexto de um corpo de conhecimentos já existente e compartilhados com o interlocutor. Geralmente, o discurso é denso e carregado de informações. Esses textos utilizam formas de comunicar que são próprias de cada disciplina: os gráficos, esquemas, símbolos, expressões matemáticas, etc. (ESPINOZA, 2006).

Santos (2007), apoiado na literatura, destaca que para fazer uso social da ciência e da tecnologia é necessário saber ler e interpretar as informações científicas e tecnológicas difundidas nas mídias sociais. Isso implica em utilizar-se de estratégias para extrair informações; aprender a fazer inferências a fim de compreender as diferentes ideias que podem estar expressas em um texto científico; compreender o papel da argumentação na construção das teorias científicas e tecnológicas e reconhecer as possibilidades e limites do texto.

Segundo Silva et al. (2011) a divulgação científica está cada vez mais frequente no cotidiano infantil. Ela se faz presente de diversas maneiras, tanto nos programas de televisão, rede de computadores, quanto por meio de publicações em revistas, como por exemplo, a revista Ciência Hoje das Crianças (CHC).

Revistas como essa tem a finalidade de divulgar a produção científica, com uma linguagem familiar, informal e acessível ao público infantil.

Nelas, nota-se que os textos tratam com naturalidade o conhecimento científico mediante a abordagem de aplicações da tecnologia, aparatos tecnológicos e de fenômenos presentes no cotidiano das crianças. (SILVA et al., 2011, p. 168).

Ler textos de divulgação científica em sala de aula pode proporcionar o contato dos estudantes com o fazer ciência, pois de acordo com Almeida (2011, p. 18):

[...] a leitura de uma revista de divulgação científica para crianças rumoreja, quando aquele que lê, que ouve, que observa faz funcionar a linguagem destacando os propósitos e despropósitos daquele que escreve.

O “rumor” descrito pela autora são as inquietações causadas por dúvida, espanto e curiosidade consequentes da leitura de uma revista científica entre as crianças. Quando o texto científico provoca os estudantes, ele deixa de ser uma simples tarefa de ler e responder a questionários sem uma reflexão do que o autor quis dizer. Ou seja, uma leitura sem "rumor” seria a decodificação mecânica do texto. 
Segundo Freire (2006a), a compreensão crítica do ato de ler não se esgota na simples decodificação da palavra ou na linguagem escrita, pois ocorre uma dinâmica entre linguagem e realidade. Sendo assim, a compreensão do texto, em uma perspectiva crítica, implica na percepção das relações entre o texto e o contexto. (FREIRE, 2006a). Ainda Freire (2006b) reforça que o processo de aprendizagem do conhecimento científico envolve muitas variáveis que seriam a cultura, os níveis de percepção que se constituem na estrutura social e os problemas de linguagem e pensamento. Ambas não podem ser dissociadas da estrutura e entre si.

Além de envolver diferentes conhecimentos, a leitura de textos de divulgação científica requer conhecimento da própria linguagem científica. Conforme Santos (2007), o discurso científico é um gênero de discurso que foi construído socialmente pelos cientistas em sua prática. Quanto mais o estudante conhecer esse gênero, maior será sua acessibilidade a ele.

Ensinar ciência significa, portanto, ensinar a ler sua linguagem, compreendendo sua estrutura sintática e discursiva, o significado de seu vocabulário, interpretando suas fórmulas, esquemas, gráficos, diagramas, tabelas etc. (SANTOS, 2007, p. 484).

Freire (2006b) faz uma crítica a quem diz que é inviável ou impossível trabalhar de modo dialógico com conhecimentos de caráter científico e técnico. Ele dá como exemplo que muitos dizem que não é possível dialogar a propósito de $\mathrm{H}_{2} \mathrm{O}$, pois a composição da água não pode ser $\mathrm{H}_{4} \mathrm{O}$. Porém em lugar da memorização mecânica, é necessário que o educando perceba criticamente o sentido do saber como busca permanente. Para tanto, faz-se necessário que se discuta a respeito do significado desse conhecimento científico, a sua dimensão histórica, sua inserção no tempo e sua instrumentalidade. Tudo isto é tema de indagação, de diálogo:

O que se pretende com o diálogo não é que o educando reconstitua todos os passos dados até hoje na elaboração do saber científico e técnico. Não é que o educando faça adivinhações ou que se entretenha num jogo puramente intelectualista de palavras vazias. $\mathrm{O}$ que se pretende com o diálogo, em qualquer hipótese (seja em torno de um conhecimento científico e técnico, seja de um conhecimento 'experiencial'), é a problematização do próprio conhecimento em sua indiscutível reação com a realidade concreta na qual se gera e sobre a qual incide, para melhor compreendê-la, explicá-la, transformá-la. (FREIRE, 2006b, p. 52).

Para Freire (2006b) a problematização é a reflexão exercida sobre um conteúdo, fruto de um ato, ou sobre o próprio ato, a fim de agir melhor diante da realidade. É a problematização das relações indicotomizáveis entre o ser humano e o mundo. A problematização não é da relação direta ser humano-mundo, mas sim das consequências dessa relação, isto é, a problematização do trabalho, obras, produtos, ideias, convicções, aspirações, mitos, arte, ciência: o mundo da cultura e da história, que condiciona os seres humanos, seus criadores.

Ao destacar a importância da problematização para a constituição do conhecimento, Freire (2006b) argumenta que nenhum cientista sistematizou seu conhecimento científico, sem ter sido problematizado, desafiado. O que não significa que toda pessoa que for desafiada, será um cientista, mas significa que o desafio é fundamental para a constituição do conhecimento. Nesse sentido, se um conhecimento científico não pode prescindir de sua matriz problematizadora, a apreensão deste não pode prescindir da problematização.

Rocha (2012) enfatiza que o acesso a informação e a possibilidade de contextualizar conteúdos e promover a problematização sobre questões atuais, estão dentre as vantagens de se utilizar textos de divulgação científica em sala de aula. Além de contribuir para o desenvolvimento de habilidade de leitura, de formas de argumentação, o domínio de conceitos e a familiarização com a linguagem científica.

Ainda o autor, apoiado no trabalho de Rocha e Martins (2011) chama a atenção para o fato de que como o texto de divulgação científica não é escrito para fins didáticos, é necessário que o professor ressignifique o mesmo. Pois as condições sociais de produção de leitura deste tipo de texto mudam, nesse sentido, o texto passa do contexto de informação para um contexto de aprendizagem.

Dessa forma, a utilização de materiais de divulgação científica como recurso didático deve ser acompanhada por uma reflexão pelos professores acerca das condições de produção destes 
materiais e de seus efeitos sobre audiências no espaço escolar uma vez que quando vão para a escola os textos de divulgação científica passam a cumprir outro papel. (ROCHA, 2012, p. 50).

Buscamos dessa maneira, com esse artigo, refletir como um texto de divulgação científica pode ser ressignificado a fim de promover a problematização em sala de aula e fomentar a leitura e a escrita.

\section{A REVISTA CHC}

A revista Ciência Hoje das Crianças foi criada no de 1986. É uma publicação do Instituto Ciência Hoje - uma organização social de interesse público sem fins lucrativos que está vinculada à Sociedade Brasileira para o Progresso da Ciência (SBPC) - cuja meta principal é a divulgação da ciência para a sociedade. Todos os artigos da revista são assinados por cientistas, jornalistas ou pelos dois, sendo que a maioria é escrito por especialistas e depois são reescritos para adequar a linguagem ao público infantil. (ALMEIDA; GIORDAN, 2014).

A revista publica sobre diversos temas, sendo eles relacionados às ciências humanas, exatas, biológicas, às geociências, ao meio ambiente, à saúde, tecnologia e cultura, se caracterizando como uma revista multidisciplinar. Tem por objetivo aproximar cientistas, pesquisadores e o público infantil, incentivando as crianças e estimulando sua curiosidade para o saber e fazer científico. (ALMEIDA; GIORDAN, 2014).

As publicações valorizam a ciência e estudos realizados por cientistas brasileiros. As imagens são de artistas escolhidos para cada artigo e as fotografias são feitas por fotógrafos contratados pela revista, a qual não tem propagandas nem anúncios de brinquedos. (ALMEIDA, 2011).

O público-alvo da revista são crianças entre 7 e 14 anos. Ela pode ser utilizada pelas crianças como material de leitura e de pesquisa escolar; pelos professores como uma alternativa além dos materiais didáticos; e para as bibliotecas como fonte de consulta. (ALMEIDA; GIORDAN, 2014).

É uma revista mensal que não é vendida nas bancas, apenas na internet de forma avulsa ou como assinatura impressa e digital. Até 2014, mais de 60 mil escolas públicas do Brasil recebiam a revista em suas bibliotecas. (ALMEIDA; GIORDAN, 2014). Atualmente, a revista impressa deixou de ser enviada para as escolas. De acordo com três bibliotecárias responsáveis pelas bibliotecas de diferentes escolas públicas municipais de Florianópolis, a última revista CHC recebida foi a de dezembro de 2015. A chefia das Bibliotecas Escolares Municipais confirma que as revistas CHC eram enviadas diretamente para as escolas e hoje nenhuma delas tem recebido as edições ${ }^{1}$. As escolas públicas deixaram de receber a versão impressa como também a versão digital da mesma. Vale ressaltar que parte da revista está disponível na Rede Digital, no entanto, é acessível integralmente para assinantes ou por compra avulsa (www.chc. org.br) $)^{2}$.

De acordo com Almeida e Giordan (2014), a revista CHC, juntamente com as revistas Mundo Estranho e Recreio, possuíam a maior circulação nacional de revista que contém textos de ciências para crianças. Após as mudanças relacionadas a não veiculação da versão impressa e digital às escolas públicas, não temos dados quantitativos sobre sua circulação.

\section{ANÁLISE DO TEXTO DE OLHO NOS NINHOS DE HARPIAS}

A escolha do texto De olho nos ninhos de harpias, publicada na versão online da revista CHC, se deu por ser uma publicação recente, por se tratar de um texto de acesso livre na internet e apresentar conceitos de linguagem científica, tecnológica e também da estatística. $O$ texto faz menção às questões éticas e ambientais e foi assinado pela doutora em Biologia Francisca Helena Aguiar-Silva.

\footnotetext{
${ }^{1}$ Informações obtidas pelas autoras por conversa telefônica com três bibliotecárias de Escolas Públicas Municipais de Florianópolis e com a Gerente das Bibliotecas Municipais de Florianópolis, Daniela Guse Weber.

${ }^{2}$ No dia 06/08/2018, as autoras enviaram um pedido de esclarecimento sobre o não recebimento das revistas na escola através do link "fale conosco" do site chc.org.br e até o momento, não receberam resposta.
} 
O texto foi analisado por meio dos procedimentos da Análise Textual Discursiva (ATD). (MORAES; GALIAZZI, 2011). A ATD é composta por três etapas: a primeira é a unitarização, em que se pretende desconstruir o corpus de análise com a pretensão de identificar sentidos em diferentes limites de seus pormenores. Da desconstrução dos textos surgem as unidades de análise que são definidas em função dos propósitos da pesquisa. A segunda etapa é a categorização das unidades de análise. As categorias podem ser a priori, emergentes ou mistas. As categorias mistas são quando aparecem as categorias a priori e emergente. Foi identificada no texto analisado uma categoria a priori, sendo ela: linguagem matemática e estatística. Além desta, uma categoria emergiu durante o processo de análise, a saber, a relação entre ciência e tecnologia. A terceira etapa é a de comunicação, na qual se constrói um novo texto que expressa a compreensão dos pesquisadores sobre os sentidos captados nos textos originais. A etapa de comunicação consistiu na elaboração de produções textuais com ênfase interpretativa em cada uma das categorias supracitadas. A seguir apresenta-se a análise.

\section{DE OLHO NOS NINHOS DE HARPIAS - AS LINGUAGENS DA CIÊNCIA, TECNOLOGIA E ESTATÍSTICA}

\section{LINGUAGEM MATEMÁTICA E ESTATÍSTICA}

Ao longo do texto De olho nos ninhos de harpias, a linguagem matemática e estatística é recorrente, como podemos observar no excerto exposto abaixo.

Registrar o que acontece em um ninho de harpia não é tarefa fácil. Este gavião constrói seus ninhos nas árvores que chamamos de emergentes (aquelas que crescem mais de 40 metros de altura na Amazônia). Eles ficam localizados no ramo principal da árvore, em média a 32 metros de altura. Acessar estes ninhos para instalar armadilhas fotográficas é um dos maiores desafios no estudo da harpia. Para isso, precisamos de um especialista em escalar árvores com equipamentos de segurança e habilidades para se movimentar na árvore e instalar o equipamento. (AGUIAR-SILVA, 2017, n. p. grifos nossos).

O ninho das harpias é construído em locais de difícil acesso por causa da altura, então, para a compreensão desse trecho é necessário ter noções sobre o sistema métrico de medidas. De acordo com Lorenzato (2006, p. 52), a construção do conceito de medida acontece num longo processo e "que começa com a comparação visual direta entre dois objetos, passa pela conveniência da utilização de unidade de medida e finaliza na abstração de um número.” Assim, para imaginar a altura do galho da árvore a 32 metros do chão, seria necessária uma comparação mental com outro objeto na posição vertical, presente no cotidiano das crianças, que serviria como referência. Seria possível medir a altura da parede da sala de aula usando a trena e então calcular quantas paredes seriam necessárias para chegar à altura de 32 metros, ou quantos andares de um prédio equivaleriam a tal comprimento. Olhando para as árvores da escola e do seu entorno, as crianças poderiam observar as mais altas, mais baixas e fazer a estimativa da altura das mesmas a partir de referências construídas.

O texto ainda sinaliza que os ninhos ficam situados a 32 metros de altura "em média”. A média é um conceito que faz parte da linguagem estatística e sintetiza uma medida obtida a partir de dois ou mais dados num único valor. O valor médio indica um lugar centralizado em que os dados se localizam. É uma medida bastante familiar e presente no cotidiano e pode ser compreendida por estimativas. (CAZORLA, 2017). É possível, então que as crianças compreendam o conceito intuitivamente, pelo frequente uso social. Mas o entendimento formal de que a obtenção da média se dá pela "soma dos valores da variável dividida pelo número de dados envolvidos na soma” (CAZORLA, 2017, p. 69) nem sempre está claro.

Por esse motivo, o professor pode levantar questionamentos a respeito desta informação do texto. Perguntas como "se a média da altura é de 32 metros, quais poderiam ser as alturas dos ninhos pesquisados?” ou “como os cientistas chegaram à conclusão de que a média da altura dos ninhos é de 32 metros?”. A discussão sobre a informação média da altura dos ninhos suscita a reflexão a respeito das escolhas feitas pelo sujeito que escreve o texto científico. Como o texto de uma revista deve ter um limite de páginas, o cientista/escritor escolhe por sintetizar os dados. 
De 2012 a 2016, as armadilhas fotográficas funcionaram em 10 ninhos de harpia, capturando imagens do que acontecia no ninho. A análise dos dados coletados com esta técnica forneceu informações valiosas sobre como a espécie se reproduz, constrói seus ninhos e cuida dos filhotes até eles poderem voar sozinhos e irem embora. As armadilhas fotográficas estavam equipadas com um detector de movimento para registrar continuamente a atividade da harpia no ninho, inclusive no período noturno. (AGUIAR-SILVA, 2017, n. p., grifos nossos).

Ao destacar a "análise dos dados coletados", o texto evidencia que quem realiza a análise é o cientista, ao qual não basta ter acesso a índices, porcentagens, etc, é preciso interpretar, comparar e tirar conclusões. (LOPES, 2004). Sendo assim, é necessário que o pesquisador se envolva com as variáveis. Para Lopes (2004, p. 188) analisar dados "requer certa sensibilidade da pessoa que se aproxima dos dados que envolvem incerteza e variabilidade.”

O início do excerto apresenta um intervalo de quatro anos no qual a pesquisa foi realizada: 2012 a 2016. Para compreender seu significado é preciso perceber que se trata de uma variável contínua, uma medida entre dois extremos. Logo em seguida, o texto explicita que não pesquisou "todos" os ninhos de harpia de certo local, mas apenas uma amostra: 10 ninhos, que representam uma parte da população. De acordo com Cazorla (2017), a escolha da amostra envolve hipóteses, limitações e objetivos do pesquisador, por isso também seria possível conversar sobre quais seriam os motivos e limitações dos cientistas.

Além do comportamento da harpia no ninho, durante as primeiras análises, 21 espécies de aves e mamíferos foram fotografadas quando pousavam ou subiam no ninho da ave. Entre as espécies registradas, podemos destacar o tamanduá-mirim, a irara, o macaco-prego, outros gaviões e tucanos. Algumas destas espécies servem também de alimento para a harpia, mas somente o macaco-prego virou refeição quando passou em um dos ninhos da harpia, e foi registrado em fotos pela armadilha fotográfica. (AGUIAR-SILVA, 2017, n. p., grifos nossos).

O cientista, ao colocar uma armadilha fotográfica para observar harpias, acabou por observar outras muitas espécies. $\mathrm{O}$ fato de outros animais aparecerem no ninho poderia ser compreendido como um problema, afinal o cientista tinha a intenção de observar apenas as harpias. No entanto, o texto trata da necessidade de compreender o comportamento dos animais e tudo o que acontece no entorno do ninho e que influencia na sua reprodução. Esse fato é uma surpresa do texto, pois quem escolhe ler um artigo de revista sobre "harpias" espera saber mais sobre tal espécie. No entanto, ao observar as imagens contidas no artigo, o leitor percebe a fotografia de muitos animais e não de harpias. Talvez as "não-fotografias" de harpias sejam uma forma de aguçar a curiosidade do leitor que segue diretamente para a leitura das legendas das imagens para saber "por que tem tamanduá, macaco e urubu no ninho de uma harpia?” De maneira interessante e contextualizada é possível compreender a interdependência das espécies e sua cadeia alimentar: o tamanduá se alimenta das formigas que infestam o ninho, o macaco também busca alimento no ninho, mas acaba se tornando alimento das harpias. Os "percalços" da pesquisa não foram descartados pela pesquisadora e acabaram se tornando parte dos “dados". Estes fatores mostram o quanto é importante o olhar para o contexto da pesquisa e não apenas para dados isolados.

O artigo termina sem apontar para resultados da pesquisa, mas sugere a importância do trabalho para a preservação da harpia e de outros tipos de gaviões. Ao ler e refletir sobre o texto, a criança pode tirar suas conclusões e construir seus próprios argumentos científicos, que são diferentes de argumentos do senso comum.

Nessa categoria foram discutidos conceitos caros a estatística. Percebemos que o texto analisado permite que o professor problematize com seus alunos esses conceitos de maneira significativa, de modo que estará contribuindo com o letramento estatístico e fomentando a leitura e escrita.

\section{A RELAÇÃO ENTRE CIÊNCIA E TECNOLOGIA}

No decorrer do texto De olho nos ninhos de harpias, observamos que as relações entre a ciência e a tecnologia estão contidas expressivamente. Podemos perceber essa presença já no primeiro parágrafo do texto: 
Um equipamento que permite observar bem de perto a vida dos animais na floresta sem ter que interferir no comportamento deles. Com as armadilhas fotográficas não é necessário pegar o animal, apenas imagens ou vídeos são coletados. (AGUIAR-SILVA, 2017, n. p., grifos nossos).

Esse excerto permite-nos problematizar a compreensão que considera a tecnologia como a extensão do corpo humano. Isto é, por meio desse trecho podemos elucidar como as armadilhas fotográficas nos possibilitam "ver” melhor. Observar lugares de difíceis acessos e alguns até inóspitos.

Ernst Kapp foi um filósofo que tratou a técnica como projeção dos órgãos humanos. Segundo ele existe uma relação intrínseca entre os aparatos tecnológicos e os órgãos, pois nos instrumentos o ser humano se reproduz continuamente a si mesmo. $\mathrm{O}$ fator de controle é o órgão do qual utilidade e poder devem ser aumentados. Dessa maneira, a forma apropriada do instrumento deve ser derivada de tal órgão. O gancho é a "cópia” de um dedo dobrado; o prato, a representação do oco de uma mão; o remo e o arado a extensão dos braços, e por esse excerto a armadilha fotográfica seria a extensão dos olhos. (MITCHAM, 1989).

Por meio desse trecho, o professor pode deliberar sobre a história da tecnologia, de como das simples técnicas, esse conhecimento foi evoluindo para um campo sistematizado que caracteriza o nosso contexto atual. Podendo a partir dessa discussão, avançar um pouco sobre a compreensão de como as técnicas e tecnologias influenciaram o desenvolvimento social, assim como o desenvolvimento social influenciou o desenvolvimento científico e tecnológico.

Pacey (1990) diz que o avanço tecnológico é concebido por muitos como a parte mais importante do progresso. Alguns chamam de misticismo da máquina. Cada era é concebida de acordo com a tecnologia dominante daquela época e se estende até às origens da história do ser humano. Por exemplo, pensamos a Idade da Pedra, do Bronze, e posteriormente a Idade do Ferro, como uma progressão técnica lógica que acarreta na evolução social e cada era pensamos nos efeitos da técnica sobre os assuntos humanos e não consideramos o contrário.

É possível voltar-se para a história de qualquer invento e expor como a forma que o desenvolvimento organizativo provocou uma nova tecnologia, ao invés de mostrar como os desenvolvimentos tecnológicos cresceram um sobre o outro influenciando a mudança social. (PACEY, 1990).

De acordo ainda com Pacey (1990), baseado na literatura, a maioria dos artefatos é feito com propósitos específicos, mas muitos exercem influências que ninguém havia esperado ou previsto. A realidade é que talvez seja mais fácil de compreender se pensarmos na prática tecnológica em relação aos seus componentes constituintes. Desse modo, a inovação pode ser vista como o resultado de um ciclo de ajustes mútuos entre os fatores sociais, culturais e técnicos. O ciclo pode até começar com uma ideia técnica ou uma mudança radical na organização, mas haverá interação com outros fatores ao aperfeiçoar a inovação. (PACEY, 1990).

Isto se aplica às Idades da Pedra e do Bronze, como também à revolução industrial, por exemplo. As explicações que se enfocam no desenvolvimento de ferramentas apenas são insuficientes, pois existe a necessidade de reconhecer todo o complexo de agentes que compõe o desenvolvimento de tal ferramenta. Desse modo, o entendimento do desenvolvimento da tecnologia não pode ser apenas entendido somente pela influência de ferramentas e as técnicas, mas também por esses agentes que tem nos levado a avanços espetaculares. (PACEY, 1990).

A partir desse trecho, o professor também pode trabalhar a questão da observação na ciência. Nos currículos de ciência é comum encontrarmos uma visão tendenciosamente empirista-indutivista, seguida de instruções destinadas aos estudantes, tais como: fazer observações repetidas, observar com atenção, selecionar observações importantes, etc. Questionar essa visão sobre a observação, não tem o intuito de desvalorizar o seu papel, mas de reapreciá-lo na construção do conhecimento. Os empiristas clássicos afirmam que a ciência começa com a observação, de forma que o observador deve registrar de modo fidedigno tudo aquilo que pode ver. A observação nesse caso deve ser destituída de significado, ou seja, deve ser puramente neutra (PRAIA et al., 2002).

Essa compreensão traz consequências diretas ao ensino. Por exemplo, os estudantes podem acreditar que por meio da observação meticulosa, a aprendizagem pode ser alcançada de imediato e que conceitos 
podem ser compreendidos e construídos apenas pela observação. Nesse sentido, o professor ao trabalhar com esse texto pode propor uma discussão com os seus alunos. A observação, dentro da ciência, não é obrigatoriamente o ponto de partida, mas se ela se caracterizar dessa forma em algum contexto científico, ela deve ser considerada provisória, e não como verdade ou certeza absoluta. As observações científicas, em sua maioria, envolvem alguma preparação prévia. Isto é, elas não são realizadas em função da atenção espontânea, sendo muito importante a definição prévia daquilo que se pretende observar. Observar provoca uma escolha, de modo que o fato científico supõe uma intenção, uma seleção criteriosa e fundamentada, de como representar o fato e a escolha de instrumentos, como prolongamento teórico, que forneçam medidas. Em síntese, o fato científico depende da elaboração teórica e tecnológica. (PRAIA et al., 2002).

Em consonância com os autores supracitados, o professor pode questionar os seus estudantes se observar por meio de uma armadilha tecnológica é o mesmo que observar com os nossos olhos; se esse tipo de observação é destituído de teorias e conjecturas. O professor pode usar também o título do texto para deliberar essa questão com os estudantes: De olho nos ninhos de harpias.

O título do texto destaca que o tema principal da reportagem é “como” observar um ninho de harpia. Assim, para compreender que observar um ninho de harpia trata-se de uma tarefa difícil, seria importante que, antes da leitura, os estudantes soubessem o que é uma harpia, tendo conhecimento mínimo da sua envergadura e da altura do vôo e do ninho deste animal.

Questionar os alunos sobre “quem já observou um ninho de algum pássaro” e pedir relatos de suas experiências seria um passo essencial para leitura desse texto. Afinal, a observação de um ninho de pássaro, mesmo que o mesmo seja pequeno, é uma tarefa difícil. Tal dificuldade ocorre pela altura dos locais escolhidos pelas aves para construir seus ninhos e o difícil acesso aos mesmos. "E como seria possível observar o ninho da harpia, uma das maiores e mais pesadas aves de rapina, que constrói seus ninhos em árvores de até 40 metros de altura?”

A observação é entendida como um processo seletivo, de forma que a pertinência da observação está ligada ao contexto de estudo. Sendo necessário ter ideias ou hipóteses do que se espera observar. Vemos o mundo por meio de lentes teóricas constituídas a partir de conhecimentos anteriores. O conhecimento teórico possibilita a interpretação do observado. Desse modo é importante desenvolver estratégias no ensino de ciências que tenham por objetivo problematizar o significado da observação. (PRAIA et al., 2002).

No excerto abaixo, podemos problematizar o que é método na ciência:

Este método é bastante eficiente, mesmo quando os registros precisam ser feitos em lugares muito altos ou escondidos. As espécies são registradas por meio da fotografia ou filmagens, aumentando a confiabilidade do registro. As fotos e imagens são capturadas de dia ou de noite, pois o equipamento pode ser programado para funcionar 24 horas. (AGUIAR-SILVA, 2017, n. p., grifos nossos).

Almeida e Giordan (2014) destacam que os textos comumente usados nas aulas de ciências têm um tipo de discurso particular, caracterizado pela neutralidade e uma atitude de certeza. Neste excerto do texto é possível perceber que o método utilizado é apresentado como eficiente e mais confiável. Ao falar em "maior confiabilidade” a autora do artigo supõe que existe uma parte não confiável, afinal "maior confiabilidade” não é o mesmo que "total confiabilidade”. A questão da "confiabilidade” traz à tona a necessidade social da ciência mostrar-se confiável. Santos (2007, p. 484) reforça que se a ciência for vista como verdadeira e acabada "os alunos terão dificuldade de aceitar a possibilidade de duas ou mais alternativas para resolver um determinado problema”. Portanto, nesse ponto valeria uma discussão sobre o que é confiável ou não se tratando de ciência.

Cupani (2018, p. 134) enquadra em seu livro Sobre a ciência: estudos de filosofia da ciência, o método científico geral como um tópico controverso. Ele destaca que o elemento mais criticado da imagem da ciência tradicional é a convicção de que existe um método científico que "singulariza a atividade científica, garantindo a produção do conhecimento.” Podemos encontrar essa compreensão em todos os níveis de ensino, em que fatos científicos dão significados às teorias, sendo a observação a etapa mais importante do dito método científico. (PRAIA et al., 2002). 
Ainda, Gil Pérez et al. (2001) identificaram algumas visões deformadas a respeito do trabalho científico, desse modo, elencaram aspectos consensuais que devem ser evitados sobre como a ciência funciona. Em síntese as visões deformadas da atividade científica são as seguintes: compreensão empírico-indutivista e ateórica; aproblemática e ahistórica; exclusivamente analítica; acumulativa de crescimento linear; individualista e elitista e socialmente neutra da ciência. Como os próprios autores reforçam, é importante ter consciência que essas visões deformadas não são autônomas, pelo contrário, elas aparecem relacionadas entre si.

Mais especificamente, dentre essas visões “deformadas” está a visão rígida (podendo ser classificada também como algorítmica, exata, infalível, etc). O método científico é apresentado como um conjunto de etapas que deve ser seguido mecanicamente. Essa visão desconsidera que nesse processo está envolvida a criatividade do cientista, dúvidas, o caráter tentativo, além de que não existe apenas um método, mas os métodos científicos. (GIL PÉREZ et al., 2001).

Gil Pérez et al. (2001) apresentam algumas características essenciais da atividade científicas que devem ser pontuadas, como: a desmistificação da ideia de que existe apenas um método científico; que o conhecimento advém de dados puros; destacar o papel das hipóteses; a procura da coerência global e o caráter social da ciência.

Conseguir uma melhor compreensão do trabalho científico tem, em si mesmo, um indubitável interesse, em particular para os que são responsáveis, em boa medida, pela educação científica de futuros cidadãos de um mundo marcado pela ciência e pela tecnologia. (GIL PÉREZ et al., 2001, p. 130).

No próximo excerto é apresentado um breve histórico da armadilha fotográfica:

O primeiro registro desse tipo de técnica de que se tem notícia aconteceu no início do século 19, quando um fotógrafo curioso chamado George Shiras, lá pelos anos de 1890, instalou fios camuflados e uma lâmpada de flash, acoplada a câmera fotográfica da época, para capturar as fotos de animais durante a noite. O próprio animal disparava a câmera e o flash quando esbarrava nos fios estendidos na floresta; por isso, o equipamento ganhou o nome de armadilha fotográfica. $O$ uso dessas armadilhas por cientistas começou em 1920, por Frank Chapman na ilha de Barro Colorado, no Panamá, quando tentava registrar mamíferos terrestres raros de serem observados. (AGUIAR-SILVA, 2017, n. p., grifos nossos).

Esse trecho permite que o professor problematize a compreensão de que a tecnologia é apenas uma aplicação direta do conhecimento científico. George Shiras foi um pioneiro nesse tipo de fotografia, porém podemos chamá-lo de amador, visto que o mesmo não tinha uma formação específica nessa área. Segundo Wender (2015) em uma reportagem na National Geographic, para fotografar à noite, Shiras copiou uma técnica de caça que aprendeu com a tribo Ojibwa. Essa técnica se chama lanterna e consiste em colocar fogo em uma panela na frente de uma canoa, com o caçador sentado na proa. Pelo brilho se distingue o animal, o qual tem a atenção capturada pelas chamas, fazendo com que ele fique parado. Na parte de trás da canoa, o caçador precisa mirar entre os olhos do animal, que se destacam como dois faróis luminosos. Na versão fotográfica, o fogo é substituído por uma lâmpada de querosene e o gatilho do rifle pela liberação do obturador da câmera.

A técnica é muito mais antiga que a ciência como uma atividade transformadora, a capacidade técnica representou uma importante vantagem na evolução humana, enquanto que a capacidade científica era pouco relevante para a maioria. A tecnologia foi reconhecida como técnica cientificamente fundamentada muito mais tardiamente. A tecnologia baseada na ciência tem se multiplicado desde o século XX. No entanto, a tecnologia contemporânea não deve ser considerada como uma simples aplicação da ciência. (ACEVEDO; GARCÍA-CARMONA, 2016).

A visão descontextualizada, socialmente neutra da ciência pode reforçar a ideia de que a tecnologia é mera aplicação da ciência. Podemos questioná-la, por exemplo, com reflexões relacionadas ao desenvolvimento histórico da ciência e da tecnologia. Pois a atividade técnica precede a atividade científica. Dessa forma pode-se começar a romper com a ideia de que a tecnologia é subproduto da ciência, que reforça o caráter neutro. (FERNANDÉZ et al., 2003). 
Essa categoria permite que o professor problematize muitas compreensões a respeito da ciência e da tecnologia que são consideradas como visões “distorcidas”, “deformadas”, e que são historicamente difundidas pelas mídias sociais. Além de permitir uma compreensão mais profunda sobre a atividade científica e tecnológica.

\section{REFLEXÕES FINAIS}

O texto analisado De olho nos ninhos de harpias nos mostra que é possível articular o ensino de ciências e matemática com a leitura de textos. Pois, mais do que decodificar e memorizar palavras e conceitos, ensinar ciências e matemática é também ensinar a ler e compreender a palavra e a realidade.

A análise suscitou que, por meio da leitura crítica do texto é possível trabalhar, além do conteúdo de biologia, a questão da estatística e as relações entre ciência e tecnologia. Também mostrou que essa possibilidade pode acontecer desde os anos iniciais do ensino fundamental, sendo imprescindível para o entendimento de como funciona a atividade científica e tecnológica.

Os textos de divulgação científica trazem relações dinâmicas entre questões ambientais, políticas, sociais, econômicas, éticas, culturais e tecnológicas, que envolvem a leitura da palavra e a leitura do mundo defendida por Freire (1996). Freire (2006a) nos diz que a compreensão crítica do ato de ler alonga-se e antecipa-se na inteligência do mundo, de modo que não se esgota na decodificação da palavra. A leitura do mundo precede a leitura da palavra, sendo que a leitura da palavra não pode anteceder a continuidade da leitura do mundo. Ocorre assim, uma dinâmica entre a linguagem e realidade, pois a compreensão que se pretende alcançar do texto implica a percepção entre as vinculações do texto e o contexto.

A leitura crítica de textos científicos na escola permite que a ciência faça sentido, que seja vista como uma produção humana, histórica, cheia de significados e linguagens. Por acreditar nisso, o trabalho que realizamos nesse artigo primou por mostrar que um texto de divulgação científica requer um leitor letrado em diferentes linguagens enquanto permite muitas leituras. Por isso, é preciso ler num contexto e dar voz aos diferentes sentidos produzidos a partir da leitura.

Os textos de divulgação científica podem ser trabalhados por meio de estratégias de leituras. Segundo Correia e Sauerwein (2017) há poucas pesquisas que propõem e avaliam atividades de ensino que tenham o intuito de desenvolver a articulação entre a leitura de texto de divulgação científica e o ensino de conteúdos científicos, por meio de estratégias de leitura. Além dos conteúdos científicos, destacamos que textos de divulgação científica podem possibilitar a abordagem da história e filosofia da ciência e interação sobre a ciência, tecnologia e sociedade.

\section{AGRADECIMENTOS}

O presente trabalho foi realizado com apoio da Coordenação de Aperfeiçoamento de Pessoal de Nível Superior - Brasil (CAPES) - Código de Financiamento 001 e com o apoio da Fundação de Amparo à Pesquisa e Inovação do Estado de Santa Catarina- FAPESC.

\section{REFERÊNCIAS}

ACEVEDO, J. A.; GARCÍA-CARMONA, A. Una controversia de la Historia

de la Tecnología para aprender sobre Naturaleza de la Tecnología: Tesla vs. Edison- La guerra de las corrientes. Enseñanza de las Ciencias, Barcelona, v.1, n. 34, p. 193-209, jan./abr. 2016.

AGUIAR-SILVA, F. H. De olho nos ninhos de harpias. Ciência Hoje das Crianças, 19 jun. 2017. Disponível em: http://chc.org.br/de-olho-nos-ninhos-de-harpias/. Acesso em: 31 jul. 2018 
ALMEIDA, S. A. Interações e práticas de letramento mediadas pela revista Ciência Hoje das Crianças em sala de aula. 2011, 268 f. Tese (Doutorado em Educação) - Faculdade de Educação, Universidade de São Paulo, São Paulo, 2011.

ALMEIDA, S. A.; GIORDAN, M. A revista Ciência Hoje das Crianças no letramento escolar: a retextualização de artigos de divulgação científica. Educação e Pesquisa, São Paulo, v. 40, n. 4, p. 9991014, out./dez. 2014.

CAZORLA, I. et al. Estatística para os anos iniciais do ensino fundamental [livro eletrônico]. Brasília: Sociedade Brasileira de Educação Matemática - SBEM, 2017.

CHASSOT, A. Alfabetização científica: questões e desafios para a educação. Ijuí: Unijuí, 2006.

CORREIA, D.; SAUERWEIN, I. P. S. As leituras de textos de divulgação científica feitas por licenciandas no estágio supervisionado em física. Revista Brasileira de Ensino de Física, São Paulo, v. 39, n. 3, p. 1-16, jul./set. 2017.

CUPANI, A. Sobre a ciência: estudos de filosofia da ciência. Florianópolis: UFSC, 2018.

ESPINOZA, A. La especificidad de las situaciones de lectura en "naturales". Lectura y vida, Buenos Aires, v. 27, n. 1, p. 6-17, mar. 2006.

FERREIRA, L. N. A.; QUEIROZ, S. L. Textos de divulgação científica no ensino de ciências: uma revisão. ALEXANDRIA Revista de Educação em Ciência e Tecnologia, Florianópolis, v. 5, n. 1, p. 3-31, jan./abr. 2012.

FREIRE, P. A importância do ato de ler: em três artigos que se complementam. São Paulo: Cortez, 2006a.

FREIRE, P. Extensão ou comunicação? São Paulo: Paz e Terra, 2006b.

FREIRE, P. Pedagogia da autonomia: saberes necessários à prática educativa. São Paulo: Paz e Terra, 1996.

GIL PÉREZ, D. et al. Para uma imagem não deformada do trabalho científico. Ciência \& Educação, Bauru, v. 7, n. 2, p. 125-153, jul./dez. 2001.

LOPES, C. A. E. Os desafios para educação estatística no currículo de matemática. In.: LOPES, C. A. E.; COUTINHO, C. Q. S.; ALMOULOUD, S. A. (orgs.). Estudos e reflexões em educação estatística. Campinas: Mercado de Letras, 2010. p. 47-64.

LOPES, C. A. E. Literacia estatística e o INAF 2002. In.: FONSECA, M. C. F. R. (org.). Letramento no Brasil: habilidades matemáticas. São Paulo: Global, 2004. p. 187-197.

LORENZATO, S. Educação Infantil e percepção matemática. Campinas: Autores Associados, 2006.

MITCHAM, C. ¿Qué es la filosofia de la tecnología? Espanha: Anthropos, 1989.

MORAES, R.; GALIAZZI, M. C. Análise textual discursiva. Ijuí: Unijuí, 2011.

PACEY, A. La cultura de la tecnología. México: Fondo de Cultura Económica, 1990.

PRAIA, J. F. et al. Problema, teoria e observação em ciência: para uma reorientação epistemológica da educação em ciência. Ciência \& Educação, Bauru, v. 8, n. 1, p. 127-145, jan./jun. 2002.

ROCHA, M. B. O potencial didático dos textos de divulgação científica segundo professores de ciências. Revista Brasileira de Ensino de Ciência e Tecnologia, Curitiba, v. 5, n. 2, maio/ago. 2012.

SILVA, E. T. Ciência, leitura e escola. In.: ALMEIDA, M. J. P. M.; SILVA, H. C. (orgs.). Linguagens, leituras e ensino da ciência. Campinas: Mercado de Letras, 1998. p. 121-130.

SILVA, L. L. et al. As analogias na revista de divulgação científica Ciência Hoje Das Crianças. Ciência \& Educação, Bauru, v. 17, n. 1, p. 163-181, jan./mar. 2011.

SOARES, M. Letramento: um tema em três gêneros. São Paulo: Autêntica, 1999. 
SANTOS, W. L. P. Educação científica na perspectiva de letramento como prática social: funções, princípios e desafios. Revista Brasileira de Educação, Rio de Janeiro, v. 12, n. 36, p. 474-492, set./ dez. 2007.

VITOR, F. C.; SILVA, A. P. B. Alfabetização e letramento científicos: consensos e controvérsias. Revista Brasileira de Estudos Pedagógicos, Brasília, v. 98, n. 249, p. 410-427, maio/ago. 2017.

WENDER, J. Meet grandfather flash, the pioneer of wildlife photography. National Geographic, 20 set. 2015. Disponível em: https://www.nationalgeographic.com/photography/proof/2015/11/20/meetgrandfather-flash-the-pioneer-of-wildlife-photography/. Acesso em: 18 ago. 2018.

ZANETIC, J. Física e Arte: uma ponte entre as duas culturas. Pro-Posições, Campinas, v. 17, n. 1, p. 39- 57, jan./abr. 2006. 